\title{
INTERNATIONAL CONFERENCE \\ “STRENGTH AND RELIABILITY OF TRANSIT PIPELINES" (MT-2008)
}

The International Conference on Strength and Reliability of Transit Pipelines was held on July 5-7, 2008 at the Pisarenko Institute of Problems of Strength of the National Academy of Sciences of Ukraine. The Conference has been organized by the Pisarenko Institute of Problems of Strength with the support of the Ministry of Fuel and Energy of Ukraine, National Joint Stock Company "NaftoGaz of Ukraine," the Scientific Council for the Solids Mechanics under the Department of Mechanics of the National Academy of Sciences of Ukraine, the Research Coordinating Expert Council for Problems of Life and Safe Operation of Structures, Facilities, and Machinery under the National Academy of Sciences Presidium, as well as with the assistance provided by the leading research institutes, organizations and companies engaged in the design, construction, operation, maintenance, and scientifictechnological support services for transit pipelines.

The Conference major objective was to cover (i) the currently available approaches to the assessment of structural strength and life extension for pipelines, (ii) the advanced diagnostic methods, (iii) the research efforts to determine the limiting state of pipelines, and (iv) the scientific and normative support for the design and operation of pipelines.

More than a hundred scientists and experts from research institutes, universities, design and engineering companies and industrial enterprises took part in the Conference proceedings.

The Conference Program included 76 reports, the authors representing Belarus, Belgium, Brazil, France, Germany, Greece, Hungary, Italy, Latvia, the Netherlands, Russia, Slovenia, the UK, the USA, and Ukraine. The reports presented the results of fundamental and applied research efforts focusing on the following issues:

- the limiting state criteria, structural strength and service life determination;

- the diagnostics, corrosion protection, integrity management;

- the damage assessment methods, the influence of defects, the properties of metal and welds upon long-time operation;

- the risk analysis, probabilistic methods, failure statistics and assessment of failure effects;

- the influence of complex geotechnical features and taking them into account;

- the operation experience and problems, failure cases, service life extension.

According to the Program Committee resolution, the reports made at the Conference will be published in the Journal Problemy Prochnosti (Problems of Strength) and relevant issues of the Reliability and Life of Machinery and Facilities Collected Papers.

The Program Committee believes that the publication of the reports will facilitate a closer cooperation between the scientific community and industrial companies and engineering organizations in tackling the problems of safe operation, structural strength, and service life of trunk pipelines and will contribute to further research and development efforts along this avenue.

I. A. Makovetskaya Cand. Sci. (Eng.)

Executive Secretary

of the Organizing Committee

Translated from Problemy Prochnosti, No. 5, pp. $5-6$, September - October, 2009. Original article submitted January 5, 2009. 